\title{
"MC's de verdade não desejam sociedades sem diversidade": o rap LGBT nas aulas de língua inglesa
}

\author{
"MC's de verdad no desean sociedades sin diversidad": el \\ rap LGBT en las clases de lengua inglesa
}

\section{"Real MCs do not wish for societies without equality": queer rap in the English language classes}

\author{
Felipe Trevisan Ferreira ${ }^{1}$ \\ Vera Lúcia Lopes Cristóvão²
}

\begin{abstract}
RESUMO: Os documentos que regulam a prática docente apontam para a escola enquanto formadora de cidadãos críticos, a partir de uma perspectiva multicultural e socialmente engajada (BRASIL, 1996, 2000, 2017). Nesse sentido, o gênero canção-rap LGBT aparece como uma ferramenta para os professores de idiomas, no sentido de proporcionar a discussão dos problemas sociais que envolvem a LGBTfobia. Assim, o presente artigo tem por objetivo analisar a organização dos textos pertencentes ao gênero canção-rap cujo conteúdo temático aborda a questão da diversidade sexual, tanto em língua portuguesa quanto em língua inglesa, de modo a propor reflexões acerca do papel que esse gênero pode ter para as aulas de Língua Inglesa. Ademais, buscamos analisar também as implicações do contexto de ação para a mobilização dos mundos discursivos e dos arquétipos psicológicos. Essa pesquisa é descritiva, de cunho interpretativista e se insere no quadro teórico metodológico do interacionismo sóciodiscursivo (ISD). As análises foram feitas com base nas categorias propostas por Bronckart (2003), a saber: contexto de ação, plano textual global e os tipos de discurso. Os resultados apontam o trabalho com o gênero canção-rap LGBT como uma maneira de abordar as sexualidades não-hegemônicas nas aulas de língua inglesa.
\end{abstract}

PALAVRAS-CHAVE: Interacionismo sócio-discursivo. Rap. LGBT. Ensino de língua inglesa.

\footnotetext{
${ }^{1}$ Mestrando do PPGEL - Programa de Pós-Graduação em Estudos da Linguagem da Universidade Estadual de Londrina (UEL). trevisanfelipe5@gmail.com.

2 Professora associada da Universidade Estadual de Londrina (UEL), membro do Programa de Pós-Graduação em Estudos da Linguagem (PPGEL-UEL) e líder do grupo de pesquisa Linguagem e Educação (desde 2002). veraluciacristovao@gmail.com
} 
"MC's de verdade não desejam sociedades sem diversidade": o rap LGBT nas aulas de língua

inglesa

RESUMEN: Los documentos que regulan la práctica docente apuntan a la escuela como formadora de ciudadanos críticos, desde una perspectiva multicultural y socialmente comprometida (BRASIL, 1996, 2000, 2017). En este sentido, el género canción-rap LGBT aparece como una herramienta para los profesores de idiomas, en el sentido de proporcionar la discusión de los problemas sociales que envuelven a la LGBTfobia. Por lo tanto, este artículo tiene como objetivo analizar la organización de los textos que pertenecen al género de canción-rap cuyo contenido temático aborda el tema de la diversidad sexual, tanto en portugués y en inglés con el fin de proponer reflexiones sobre el papel que el género puede desempenãr en las clases de lengua inglesa. Además, buscamos analizar también las implicaciones del contexto de acción para la movilización de los mundos discursivos y de los arquetipos psicológicos. Esta investigación es descriptiva, de carácter interpretativista y se inserta en el marco teórico metodológico del interacionismo socio-discursivo (ISD). Los análisis se realizaron sobre la base de las categorías propuestas por Bronckart (2003), a saber: contexto de acción, plan textual global y los tipos de discurso. Los resultados apuntan al trabajo con el género canciónrap LGBT como una manera de abordar las sexualidades no hegemónicas en las clases de lengua inglesa.

PALABRAS CLAVE: Interaccionismo socio-discursivo. Rap. LGBT. Enseñanza de lengua inglesa.

ABSTRACT: Documents that govern language teaching practice in Brazil recognize the role of the school in educating citizens critically, from a multicultural and socially engaged perspective (BRAZIL, 1996, 2000, 2017). In this sense, the genre queer rap can be considered as a tool for language teachers, in the sense of fostering the discussion about social problems that involve LGBTphobia. Thus, the present article aims at analyzing the organization of texts belonging to the genre rap whose thematic content addresses the issue of sexual diversity, both in Portuguese and English, in order to propose reflections about the role this genre can play in English language lessons. In addition, we also seek to analyze the implications of the context of action for the mobilization of discursive worlds and psychological archetypes. This research is descriptive, interpretative and falls within the theoretical framework of socio-discursive interactionism (SDI). Our analyzes were made based on the categories proposed by Bronckart (2003), namely: context of action, global textual plan and types of discourse. The results point to the work with queer raps as a way of approaching non-hegemonic sexualities in English language lessons.

KEYWORDS: Socio-discursive interactionism. Rap. LGBT. Queer. English language teaching.

\section{Introdução}


MC's de verdade não desejam sociedades sem diversidade Recupere o seu bom senso Repense bem nos fundamentos sendo verdadeiro Vai ter bicha no rap sim! E eu nem sou pioneiro (Murillo Zyess - Quebrada Queer)

Ao versar sobre o texto artístico-literário, Antônio Cândido já o posicionava em um círculo retroalimentado de influências, apontando-o como produto e produtor do meio social, concomitantemente (CÂNDIDO, 2000). De fato, vários estudiosos da Linguística Aplicada reconhecem o caráter multidisciplinar das linguagens ao criar a realidade social. Essas ideias vão ao encontro da teoria bakhtiniana, segundo a qual, não só as produções literárias, mas qualquer produção linguística reflete e refrata os valores sociais de seu contexto de produção (BAKHTIN, 1997). Para o autor, assim, o texto artístico deveria ser compreendido dentro de uma "unidade diferenciada de toda cultura de uma época" (STAM, 1992 apud NASCIMENTO; PINHEIRO, 2013).

Diante disso, é possível entender as produções de textos do gênero canção-rap como recortes culturais feitos pelo ponto de vista de sujeitos menos favorecidos pelo arranjo social vigente. Esses textos fazem parte do movimento sócio-cultural denominado hip-hop, que tem sua origem nas periferias americanas, influenciadas pela cultura africana. Apesar disso, esses textos estão muito presentes no contexto brasileiro, especialmente nas periferias (BERGAMINI; FERNANDES, 2005). Na contemporaneidade eles são caracterizados por um discurso em que

[...] seus integrantes externalizam a sua aversão à forma como se organiza a sociedade, que consideram como responsável pelas dificuldades vivenciadas no cotidiano dos cidadãos "periféricos", os que vivem em guetos, favelas ou bairros afastados das grandes cidades no Brasil e em outros países, vítimas do preconceito, discriminação, desemprego, violência policial, discriminação racial, obstáculos 

pirâmide social. (NASCIMENTO; PINHEIRO, 2013, p. 5).

Segundo Fonseca (2015), o rap está presente em todo o território brasileiro, sendo influenciado pelos ritmos característicos de cada região. No Distrito Federal, por exemplo, o rap apresenta ligações com o repente, enquanto no cenário do Rio de Janeiro, o gênero sofre influências do funk carioca. A autora ainda aponta que o rap teve três fases principais no cenário nacional: i) fase da autoafirmação, muitas vezes festiva, da negritude e da produção cultural ligada à juventude de periferia, cujos principais exponentes foram Nelson Triunfo e Thaide \& DJ Hum; ii) fase da denúncia dos problemas sociais urbanos, com uma crítica às condições de desigualdade da sociedade brasileira, marcada pelo lançamento do disco "Sobrevivendo ao Inferno", dos Racionais MC's em 1988; e iii) fase da ironia poética, com influências mais difusas, que passou a dialogar com outros estilos como o samba, o reggae, o dub e o funk - que é a fase atual.

Ademais, Parada e Fernandes (2007) ressaltam a importância de se analisar os discursos mobilizados pelos rappers em seu contexto de enunciação. Para os autores, os rappers ocupam um lugar social específico no momento da enunciação, amparados pelo preceito da originalidade, ao mobilizar elementos de cultura, tema, poética, retórica, estilo e música. Assim, os rappers formulam um discurso que "funda horizontes de significação que a história explicitará em seguida" (PARADA; FERNANDES, 2007, p. 13-14). Assim, ao fazer uso de elementos poéticos em uma linguagem complexa, os raps são responsáveis por expressar o estado de ânimo de indivíduos excluídos e marginalizados pelo arranjo social vigente (BERGAMINI; FERNANDES, 2005).

Diante disso, é possível notar o caráter pungentemente social dos raps, que carregam as marcas de conflitos identitários do sujeito pós-moderno. Esses conflitos são constantemente perpassados por questões de poder (HALL, 2005), 
especialmente para aqueles em situação de vulnerabilidade social. Essa condição é ainda mais potencializada pela intersecção das identidades não hegemônicas em um mesmo sujeito: indivíduos que são da periferia, mas também são negros, mulheres e/ou LGBTQ+ ${ }^{3}$. É nesse solo arraigado por conflitos que surgem os raps $L G B T$, ou queer raps. textos do gênero canção-rap que mobilizam o conteúdo temático da diversidade sexual e de gênero.

Assim, a presente pesquisa tem por objetivo analisar a organização dos textos pertencentes ao gênero canção-rap cujo conteúdo temático aborde a questão da diversidade sexual. Espera-se com isso tecer considerações a respeito da didatização desse gênero para o ensino de língua inglesa e oferecer alternativas que fomentem as possibilidades de participação social dos estudantes. A seguir, exploraremos o arcabouço teórico que subjaz a nossa pesquisa, e em seguida explicaremos os nossos procedimentos metodológicos. Então apresentaremos as análises propostas, seguidas de nossas conclusões.

\section{O Espaço do Rap na Escola}

Diversos autores já exploraram as potencialidades dos elementos da cultura hip-hop em experiências educacionais (AU, 2005; LENHARO, 2016; POWELL, 1991), entre outros. Para Powell (1991), as juventudes marginalizadas não se veem nos discursos que circulam na escola e, por isso, não se identificam com ela. Por conseguinte, o rap - que habita os espaços urbanos, as ruas - acabase por se configurar como uma alternativa informal aos sujeitos com identidades

\footnotetext{
${ }^{3} \mathrm{O}$ acrônimo LGBTQ+ é usado para designar pessoas que se identificam como Lésbicas, Gays, Bissexuais, Transexuais ou Queergender. O símbolo " + " é incluído como forma de reconhecer as demais formas de identidades de gênero ou sexualidades não hegemônicas que porventura não se sintam representadas por esses outros grupos. 
não-hegemônicas, deslegitimadas pela escola. De fato, os textos pertencentes a esse gênero costumam tocar questões consideradas como tabu no ambiente escolar, tais quais violência, sexo ou crime. Ao fazê-lo, os textos teriam como objetivo educar os seus ouvintes (AU, 2005). Para a juventude negra, por exemplo, o rap proporciona um grande empoderamento identitário.

Au (2005) expande a discussão ao posicionar o discurso do rap em uma posição combativa ao discurso da escola, em batalha. Nesse sentido, o rap representaria uma crítica à escola como um discurso dominante, um movimento de resistência. Para a autora, a escola é disfuncional no que diz respeito às representações identitárias e as necessidades das juventudes marginalizadas. 0 movimento hip-hop, assim, ressaltaria a necessidade de um currículo mais relevante culturalmente.

Nesse sentido, ao pensar sobre os discursos que circulam na escola a quem eles podem servir, Bourdieu e Passeron (1970) nos alertam sobre as implicações e os perigos de a escola servir como um instrumento da manutenção do status quo, ao reproduzir o sistema social vigente e, consequentemente, suas estruturas de opressão - ao invés de cumprir seu papel social, e de formar cidadãos críticos. Isso acontece, por exemplo, quando as manifestações culturais trazidas ao ambiente escolar pertencem apenas ao cânone, em detrimento de representações culturais não-hegemônicas - como o rap. Daí a importância de se incluir esse gênero nas aulas de idiomas, uma vez que o movimento Hip Hop possui o objetivo de dar vozes a sujeitos marginalizados pelo sistema, de modo que eles possam denunciar as condições em que vivem e as desigualdades presentes no país. $O$ inglês entra nessa relação como um catalisador do alcance dessas vozes, de modo a possibilitar a participação social em uma escala mais ampla ou global. 
Os documentos regulatórios do trabalho docente, como a Lei de Diretrizes e Bases (BRASIL, 1996) e os Parâmetros Curriculares Nacionais (BRASIL, 2000), reforçam as ideias de Bourdieu e Passeron (1970) ao apontar para escola como uma formadora de cidadãos críticos. Para isso, sugerem uma concepção curricular transdisciplinar e multicultural, que engloba formas contemporâneas de linguagem e conhecimentos necessários para a leitura crítica do mundo. Nesse mesmo sentido, a Base Nacional Curricular Comum (BRASIL, 2017) aponta o ensino de Língua Inglesa como uma maneira de compreender diferentes modos de ser e de se constituir identitariamente, visando explorar a relação dos cidadãos com o mundo a sua volta, em um contexto global - o que incorpora inclusive manifestações de identidades não-hegemônicas.

Pensando nas implicações socio-culturais da língua, Bakhtin e Voloshinov (1995) ampliam a discussão ao apontar que as palavras não são simplesmente palavras, mas carregam em si um valor deôntico e estão situadas no contexto da enunciação, e não em um "vácuo social" livre das estruturas sócio-culturais que as constituem:

[...] [a]s palavras não são só palavras, mas sim: sempre se apresenta aos locutores no contexto de enunciações precisas, o que implica sempre um contexto ideológico preciso. Na realidade, não são palavras o que pronunciamos ou escutamos, mas verdades ou mentiras, coisas boas ou más, importantes ou triviais, agradáveis ou desagradáveis, etc. A palavra está sempre carregada de um conteúdo ou de um sentido ideológico ou vivencial (BAKHTIN; VOLOSHINOV, 1995, p. 95).

Ao explorar as produções de canções-rap enquanto manifestações comunicativas enunciadas por um determinado sujeito em um determinado contexto de ação linguageira, justifica-se a compreensão do rap enquanto um gênero do discurso poético que se situa em uma "cadeia interminável de textos e de ações linguageiras de um grupo humano" (NASCIMENTO; PINHEIRO, 2013). Nesse sentido, a figura do rapper é compreendida enquanto um enunciador que 
materializa ações da linguagem a partir de uma perspectiva singular - que não é a hegemônica. O gênero canção-rap poderia, assim, promover

[...] leituras e escutas reflexivas e críticas sobre o contexto sócio histórico de emergência do gênero, temas, suportes, valores ideológicos agregados, modos semióticos de materialização pela dança, grafite, sons musicais, linguagem oral e escrita, assim como mecanismos de textualização e enunciativos pelos quais são materializados (NASCIMENTO; PINHEIRO, 2013, p. 3).

Diante do supracitado, os raps podem contribuir para as aulas de línguas tanto no que tange à materialidade linguística, quanto ao conteúdo temático mobilizado.

De acordo com Fonseca (2011), as canções-rap apresentam riqueza de linguagem e sofisticação poética, com elementos derivados dos gêneros tragédia ática e crônica. Esses textos contribuem para uma perspectiva multiculturalista, fomentando o desenvolvimento dos alunos no que tange à compreensão crítica dos conflitos sócio-políticos do mundo contemporâneo, como os índices de violência urbana.

Lenharo (2016) relata em sua pesquisa uma experiência de ensino de língua inglesa através do uso de uma sequência didática sobre o gênero cançãorap. Durante sua intervenção, os alunos participantes de um projeto social, no qual participavam de um time de basquetebol, elegeram uma canção-rap em língua inglesa que representasse a identidade do time. Após estudar o gênero e suas características, bem como ter acesso a vários exemplos de raps, os alunos postaram a sua escolha no blog do projeto, acompanhada por um texto em língua inglesa que justificava a escolha feita. Ao trabalhar com alunos em condição de vulnerabilidade social, a autora aponta que seu trabalho não só ampliou o conhecimento dos alunos a respeito da língua-alvo, como também fomentou 
reflexões sobre o lugar social que esses alunos ocupavam, enquanto moradores da periferia, através da perspectiva dos multiletramentos. Esse trabalho reforça, assim, a possibilidade desses textos fornecerem subsídio para a construção de identidades de sujeitos em condição de vulnerabilidade social.

Nesse sentido, assim como os raps podem servir como instrumento de reflexão acerca da posição social dos sujeitos periféricos, os raps $L G B T$ podem servir para a compreensão da problemática da LGBTfobia, cada vez mais presente na sociedade. Os índices de mortes por LGBTfobia estão em uma progressão crescente, chegando a números recordes em 2017. Ainda assim, políticas públicas que buscam trabalhar nesse sentido encontram forte resistência no cenário político. Fonseca (2011) já previa que os raps passariam cada vez mais a dialogar com os problemas sociais que circundam o universo do hip-hop, tais quais política internacional, preocupação ambiental e - que mais nos interessa nessa pesquisa - a questão da diversidade sexual e de gênero. A tendência, portanto, é que mais textos surjam nesse sentido, de modo a denunciar as mazelas das populações LGBTQ+ no cenário periférico - o que demanda que os alunos estejam prontos para dialogar com esses textos.

\section{Arcabouço Teórico-Metodológico}

Essa pesquisa é descritiva, de cunho interpretativista. Ela se insere no quadro teórico-metodológico do interacionismo sócio-discursivo (ISD), e está alicerçada na concepção enunciativa bakhtiniana. Para Bakhtin (1997), a comunicação verbal se dá através de enunciados produzidos por agentesprodutores, dentro de um gênero do discurso, inseridos em um determinado contexto sócio-cultural. 
As categorias de análise utilizadas nesta pesquisa foram propostas por Bronckart (2003). Segundo o autor, ao debruçar-se sobre uma produção textual, deve-se primeiramente analisar a relação estabelecida entre a ação de linguagem e os parâmetros do contexto sócio-histórico-cultural no qual essa ação se inscreve. A materialidade do texto, desta maneira, não pode ser analisada sem levar em consideração a organização social na qual a ação de linguagem se dá. Subsequentemente, analisa-se as capacidades mobilizadas no texto e então a condição de construção dessas capacidades.

Para os propósitos desta análise, um corpus de quatro canções-rap foi selecionado. 0 nosso critério de seleção foi o conteúdo temático mobilizado. Isto é, priorizamos canções-rap que abordassem a questão da diversidade sexual e de gênero em suas letras. Apesar de nosso foco ser a didatização do gênero para as aulas de língua inglesa, duas das canções selecionadas são brasileiras e em língua portuguesa, uma vez que entendemos que a territorialidade refletida e refratada no texto tem um papel importante na sua produção - e que as canções produzidas no contexto brasileiro apresentam características distintas daquelas produzidas em países falantes de língua inglesa.

Os textos que compõem nosso corpus são:

a) "Gay [Interlúdio]", composta e interpretada por Glória Groove, presente no disco O proceder, de 2017. 


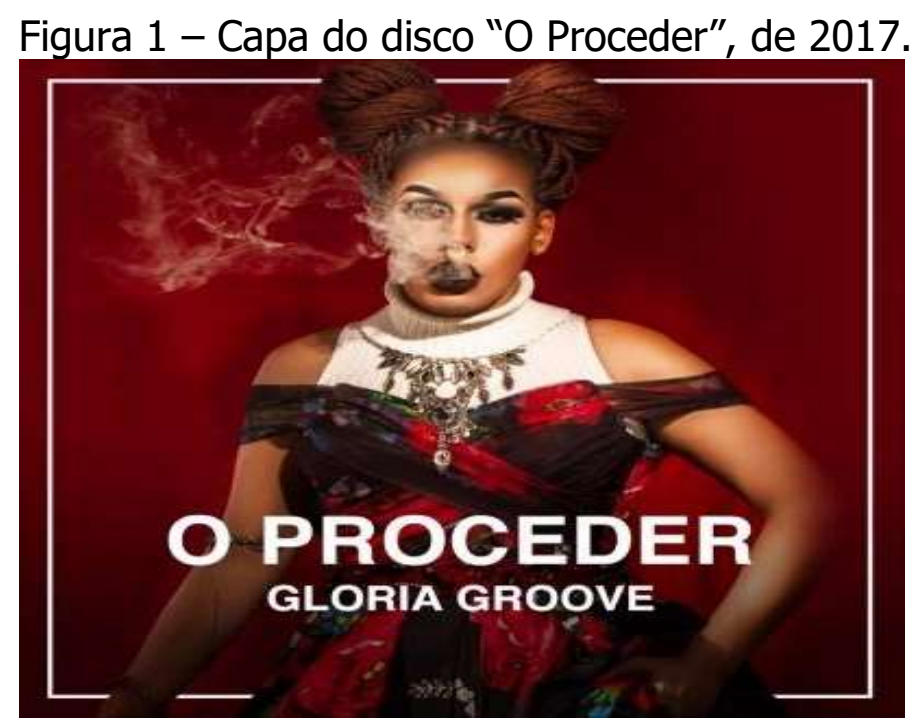

Fonte: Groove (2017).

"Quebrada Queer", composta e interpretada por Guigo, Harlley, Lucas Boombeat, Murillo Zyess, Rap Box e Tchelo Gomez, apresentada como um single (isto é, independentemente de um disco) em 2018. Para os propósitos desta pesquisa, todavia, enfocaremos os versos de Murillo Zyess.

Figura 2 - Capa do single "Quebrada Queer", de 2018.

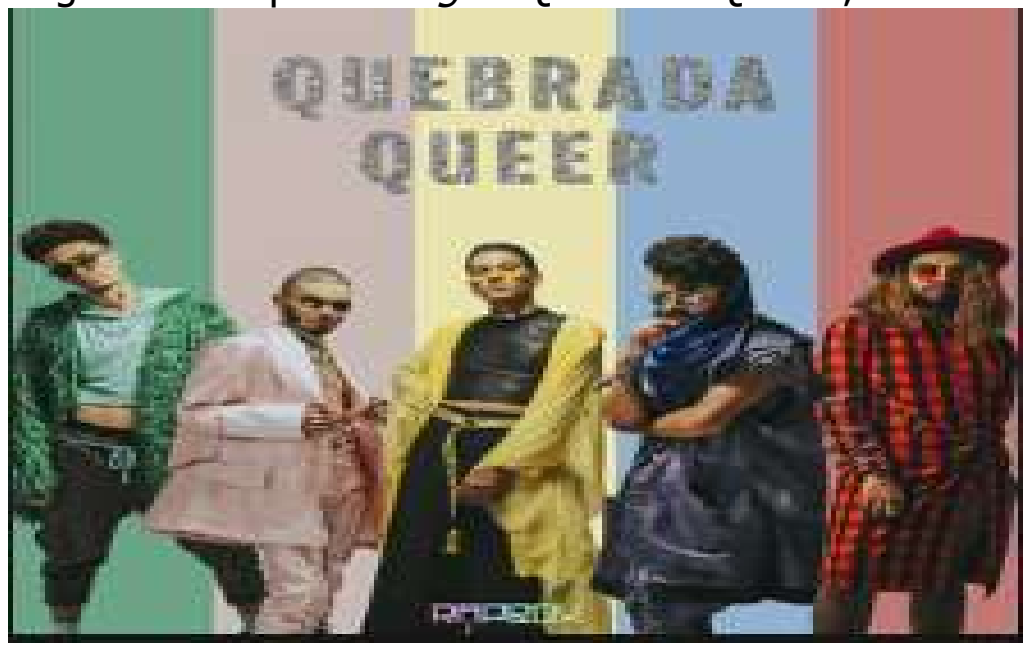

Fonte: Lado A (2018). 
b) "Same Love", composta por B. Haggerty, M. Lambert e R. Lewis e interpretada por Macklemore \& Ryan Lewis e Mary Lambert, presente no disco The Heist (2012).

Figura 3 - Capa do disco "The Heist", de 2012

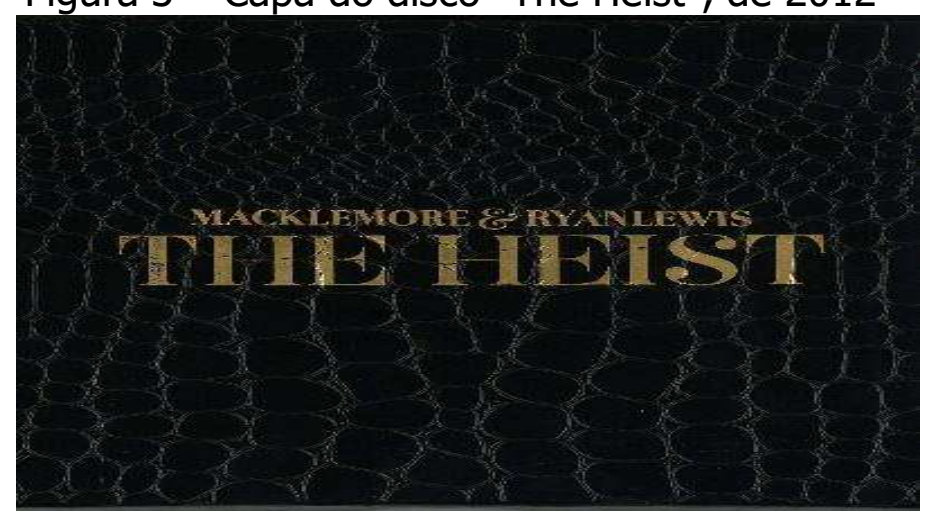

Fonte: Apple Music Preview (2018).

c) "Animal Style", composta e interpretada por Murs, presente no disco Love \& Rockets (2011), Volume 1: The Transformation .

Figura 4 - Capa do disco "Love \& Rockets, Volume 1: The Transformation".

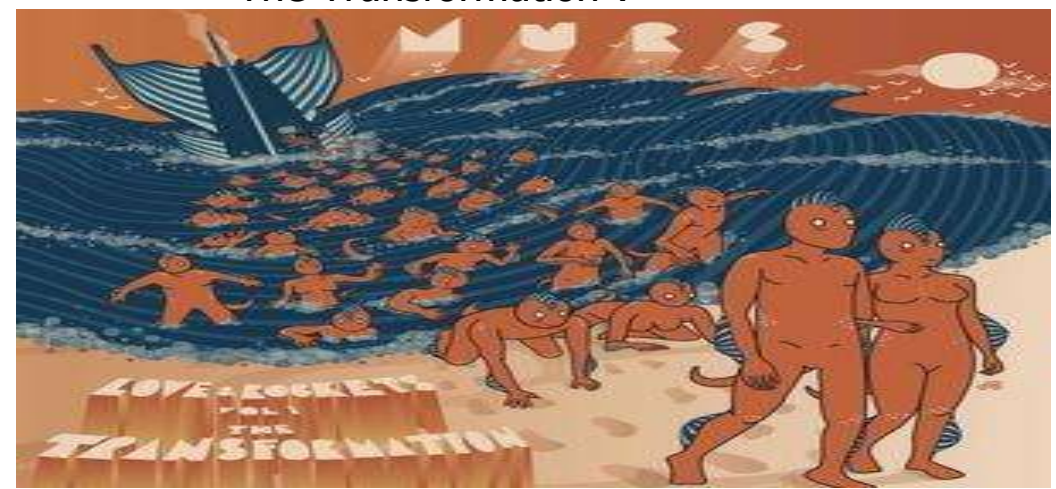

Fonte: Love... (2011).

A seguir, apresentaremos a análise dos textos do corpus selecionado. Iniciamos com uma análise do contexto de ação de linguagem no qual esses textos se inscrevem. Em seguida, analisaremos o plano textual global e os tipos Entretextos, Londrina, v. 19, n. 1, p. 109- 142 Dossiê Temático/ 2019 
"MC's de verdade não desejam sociedades sem diversidade": o rap LGBT nas aulas de língua inglesa

de discurso presentes no texto. Em conclusão discutiremos a implicação da didatização desse gênero para a discussão de diversidade sexual no ambiente escolar. 


\section{Canções-Rap em Língua Portuguesa}

Na contemporaneidade, com o advento da internet, artistas da música queer periférica vêm ganhando espaço no cenário musical, uma vez que não precisam depender dos grandes veículos midiáticos para que tenham suas vozes ouvidas (OLIVEIRA, 2017). Apesar dos grandes avanços conquistados pelos movimentos sociais LGBTQ+ no último século, indivíduos pertencentes a esse grupo ainda enfrentam violências e opressões diárias. Segundo o relatório do Grupo Gay da Bahia, em 2017 registrou-se o maior número de mortes por LGBTfobia em 38 anos. Concomitantemente, tem-se visto o avanço de pautas fundamentalistas e religiosas no cenário nacional, que visam tolher os direitos dessa população.

A periferia, enquanto espaço de criação artística e cultural, teve historicamente seu valor diminuído em relação às produções artísticas figuradas dentro do cânone, como a Música Popular Brasileira, por exemplo (LENHARO, 2016). E ainda dentro do cenário do rap nacional, a questão da homossexualidade ou da diversidade sexual foi sempre considerada um tabu. De fato, as canções-rap mais tradicionais costumavam reproduzir discursos homofóbicos e machistas. É nesse contexto social que a ação de linguagem dos textos 1 e 2 se inscrevem: são textos de sujeitos silenciados duplamente, primeiro por serem da periferia e segundo por serem LGBTQ+.

A canção-rap intitulada "Gay [interlúdio]" está presente no primeiro disco de trabalho da cantora e drag queen ${ }^{4}$ Glória Groove, "O Proceder", de 2017. No que tange à materialidade sonora da canção, o andamento dos versos é acelerado em tom de texto falado, característico do gênero. A faixa vocal é

\footnotetext{
${ }^{4}$ Drag queen é uma forma de arte performática comum no meio LGBTQ+, na qual o artista se traveste de um personagem do sexo oposto durante as suas apresentações. 
apenas acompanhada de uma faixa de interferência (adicionada intencionalmente), sem faixas instrumentais. A letra da canção é transcrita a seguir, enumerada para fins de análise:

Quadro 1 - Texto 1 - Gay [Interlúdio] (36s)

\begin{tabular}{|rl|}
\hline 1. & Essa daqui é praquelas gay \\
\hline 2. & Que no prézinho já sabia que era gay \\
\hline 3. & A criançada apontava: "Cê é muito gay" \\
\hline 4. & Já brincava com as barbie "Teu filho é gay, eu bem que te avisei" \\
\hline 5. & É praquelas gay que não sabia bem porque era ruim ser gay \\
\hline 6. & Sentiu na pele bem cedo como tratam as gay \\
\hline 7. & Já brigou com Deus "por que me fizeste gay?", queria ser alguém \\
\hline 8. & Já não temas, gay \\
\hline 9. & Aquilo que não mata fortalece um gay \\
\hline 10. & Sente o quanto te empodera ter nascido gay \\
\hline 11. & Em teus olhos um espelho onde eu me enxerguei \\
\hline 12. & É que eu também sou gay \\
\hline 13. & E levante, gay \\
\hline 14. & Que a luta ainda não acabou pras gay \\
\hline 15. & Que a nossa vitória vai ser o close, gay \\
\hline 16. & E que se eu estou aqui hoje dando voz pras gay \\
\hline 17. & É por ser gay \\
\hline
\end{tabular}

Fonte: Groove (2017).

A análise do plano textual global do Texto 1 pode ser apresentada da seguinte maneira:

a) a canção se inicia com a enunciadora especificando claramente a quem o texto se destina, os homossexuais (linhas 1-2); 
b) a enunciadora continua ao relatar uma série de violências sofridas na infância pelo grupo social no qual os destinatários se encaixam (linhas 3-7);

c) a enunciadora usa de verbos no imperativo de modo a fomentar no destinatário um processo de empoderamento baseado em sua identidade homossexual (linhas 8-10)

d) a enunciadora, através de uma metáfora, se inclui no grupo social dos destinatários (linhas 11-12)

e) o processo de empoderamento fomentado pelo texto (iniciado na linha 8) é retomado, porém desta vez com o uso da primeira pessoa do plural, que inclui também a enunciadora nesse processo de empoderamento (linhas 13-15)

f) o texto é finalizado com uma justificativa do local de fala ocupado pela enunciadora, que reforça a sua identidade homossexual (linhas 16-17).

Já a canção-rap "Quebrada Queer" foi lançada como um single pelo grupo de rappers notoriamente considerado como "o primeiro cypher ${ }^{5}$ LGBT" da América Latina. O grupo é composto por cinco rappers, todos eles assumidamente LGBT: Guigo, Murillo Zyess, Harlley, Lucas Boombeat e Tchelo Gomez. Cada um deles possui um verso dentro da canção, que não possui um refrão. As faixas instrumentais variam de acordo com o rapper em questão. Para o propósito dessa pesquisa, os versos de Murillo Zyess serão analisados, que é o segundo a se apresentar na canção. A faixa vocal possui o andamento acelerado, que é característico do rap, e é acompanhada pela faixa de percussão comum a

\footnotetext{
${ }^{5}$ Grupo de rappers. 
toda a canção. Além disso, essas duas faixas são acrescidas ora por uma faixa de sopro, ora por uma faixa de sintetizador e ora por uma faixa de piano. A letra da canção é transcrita a seguir, enumerada para fins de análise: 
Quadro 2 - Texto 2 - Quebrada Queer (5m59s), Murillo Zyess, single, Rap Box.

\begin{tabular}{|ll|}
\hline 1. & Vidas cinzentas seguidas de um longo inverno \\
\hline 2. & Muito bem preenchidas, somente com amor materno \\
\hline 3. & Entrando em paz com todos meus sentimentos internos \\
\hline 4. & Desvio de alguns crentes que dizem que eu vou pro inferno \\
\hline 5. & É que com um leão por dia me fez um guerreiro \\
\hline 6. & Não estou disposto a me calar pra agradar terceiros \\
\hline 7. & Por existências que estavam trancada em cativeiro \\
\hline 8. & Herança disso tudo é paz, e eu sou herdeiro \\
\hline 9. & Subestimado desde meu primeiro verso \\
\hline 10. & Eles disfarçam bem, são tipo lobo em pele de cordeiro \\
\hline 11. & Mas estou atento, pro opressor eu não disperso \\
\hline 12. & Minhas rimas: inseticida; preconceito deles: formigueiro \\
\hline 13. & MC's de verdade não desejam sociedades sem diversidade \\
\hline 14. & Recupere o seu bom senso \\
\hline 15. & Repense bem nos fundamentos sendo verdadeiro \\
\hline 16. & Vai ter bicha no rap sim! E eu nem sou pioneiro \\
\hline 17. & É que eu já disse, estou bem pleno \\
\hline 18. & Sou problema tipo Venom \\
\hline 19. & Esses caras acham que é rap porque estão rimando \\
\hline 20. & Vou ter que usar do meu veneno pra falar do que eu estou vendo \\
\hline 21. & Suas ideias "é" tipo Nemo, e eu estou procurando (cadê,, cadê) \\
\hline 22. & Nós "tá" aqui por cada bicha com a vida interrompida \\
\hline 23. & Por causa de homofobia, ódio e intolerância \\
\hline 24. & Resistimos no dia a dia \\
\hline 25. & Pra poder chegar o dia que prevaleça respeito, igualdade e esperança \\
\hline
\end{tabular}
Fonte: Lado A (2018).

A análise do plano textual global do Texto 2 pode ser apresentada da seguinte maneira:

a) a canção se inicia com uma descrição dos problemas pessoais pelos quais o enunciador passou, através de metáforas e da indicação do abandono paterno (linhas 1-3);

b) o enunciador sinaliza o seu distanciamento do discurso religioso, que condena a sua homossexualidade (linha 4)

c) através de uma metáfora, o enunciador aponta os desafios que enfrentou na vida (linha 5) 
d) o enunciador se posiciona a respeito da sua voz social, de como ela é recebida pela sua comunidade, e do efeito de seu posicionamento para os seus sentimentos (linhas 6-8)

e) há então uma descrição da relação do enunciador, enquanto rapper, com a sua comunidade e a sua posição frente a atitude do opressor (linhas 9-13)

f) o enunciador faz uso de verbos no imperativo para sugerir que os destinatários repensem suas conviç̧ões (linhas 14-15)

g) o enunciador demarca o lugar social que ocupa enquanto um rapper homossexual, indicando a comunidade em que se inclui (linha 16)

h) o enunciador se refere e critica outras canções-rap, através de comparações com personagens do universo cinematográfico popular (linhas 17-21)

i) a canção é finalizada com a exposição clara dos objetivos do texto e de seu papel social na construção de uma sociedade menos violenta para o seu grupo social (linhas 22-25)

Os textos 1 e 2 abordam o mesmo tema, isto é, mobilizam o mesmo conteúdo temático. Eles apresentam diversas similaridades, a começar pelo papel social do enunciador: ambos homossexuais advindos da periferia que trabalham com a produção de canções-rap. Essa similaridade está refletida na materialidade de seus textos: ambos representam verbal e explicitamente o objetivo de sua interação e o papel social que ocupam (linhas 16 e 17 no texto 1, e linhas 16 e 22-15 no texto 2). Por terem suas vozes silenciadas, parece haver uma valoração acerca da ação de fazer-se ser ouvido.

No texto 1 , a enunciadora se dirige diretamente aos homossexuais, reconhecidamente seus destinatários, ação marcada pela repetição da palavra Entretextos, Londrina, v. 19, n. 1, p. 109- 142 Dossiê Temático/ 2019 
"gay". Ao contrário disso, o enunciador do texto 2 parece se dirigir aos seus opressores. Em ambos os casos, a primeira pessoa do plural é utilizada (linha 15 no texto 1 , linhas 22 e 24 no texto 2 ) para que seja mobilizada não somente a voz do indivíduo que produz o texto, mas também de todo o grupo social ao qual ele pertence. $O$ discurso religioso também aparece presente em ambos os textos (linha 7 no texto 1 , linha 4 no texto 2), marcando a sua importância na construção do conflito para a identidade LGBT.

Tanto no texto 1 , quanto no texto 2 , as coordenadas gerais que organizam o conteúdo temático encontram-se conjuntas às coordenadas do mundo ordinário, o que pode ser verificado pela presença de dêiticos (aqui e hoje), o que os localiza no mundo discursivo do expor. Da mesma maneira, as instâncias de agentividade são mantidas em uma relação explícita com os parâmetros materiais de ação da linguagem. Os actantes, portanto, estão implicados em ambos o texto, o que caracteriza os textos 1 e 2 como pertencentes ao mundo discursivo do expor implicado.

A seguir, a análise das canções-rap que abordam a temática da diversidade sexual em língua inglesa é apresentada.

\section{Canções-Rap em Língua Inglesa}

A gênese do rap no contexto internacional remonta à vivência de jovens negros e de outros grupos marginalizados no final dos anos 70, no bairro do Bronx, em Nova York (NASCIMENTO; PINHEIRO, 2013). Ainda assim, a questão da classe social foi sempre priorizada, e a discussão de sexualidades não hegemônicas não obteve tanto espaço nesse cenário. De fato, o movimento do hip-hop era constantemente associado a discursos de intolerância e homofobia (CHONIN, 2001). Todavia, na virada do século, com a criação de eventos como Entretextos, Londrina, v. 19, n. 1, p. 109- 142 Dossiê Temático/ 2019 
"PeaceOUT World Homo Hop Festival"em 2001 e do documentário "Pick Up the Mic", de 2006, a discussão da diversidade sexual foi ganhando espaço no cenário musical do rap, com influências da teoria queer e da terceira onda do feminismo. Estabeleceu-se, assim, o subgênero chamado de Homo Hop, ou hip hop LGBT. Ainda assim, as canções do gênero de maior notoriedade são de rappers heterossexuais, como as canções que compõem o nosso corpus.

A canção-rap intitulada "Same Love" (o mesmo amor), está presente no disco "The Heist"(2012), álbum de estreia do duo de rappers Macklemore \& Ryan Lewis. Nessa canção em especial, há a colaboração da compositora e intérprete Mary Lambert durante o refrão. A canção foi utilizada como parte da campanha "Washington Referendum 74", que advogava em favor do referendo acerca da união matrimonial de pessoas do mesmo sexo no estado de Washington, nos Estados Unidos. No que tange à materialidade sonora da canção, ela apresenta um andamento reduzido com a padrão ritmo próximo de uma balada romântica, especialmente durante o refrão - com a faixa de percussão mais discreta e uma faixa de piano mais proeminente. Ainda assim, durante os versos, a canção preserva o andamento acelerado da faixa vocal, que se assemelha à língua falada. A letra da canção é transcrita a seguir, enumerada para fins de análise: 
Quadro 3 - Texto 3 - Same Love

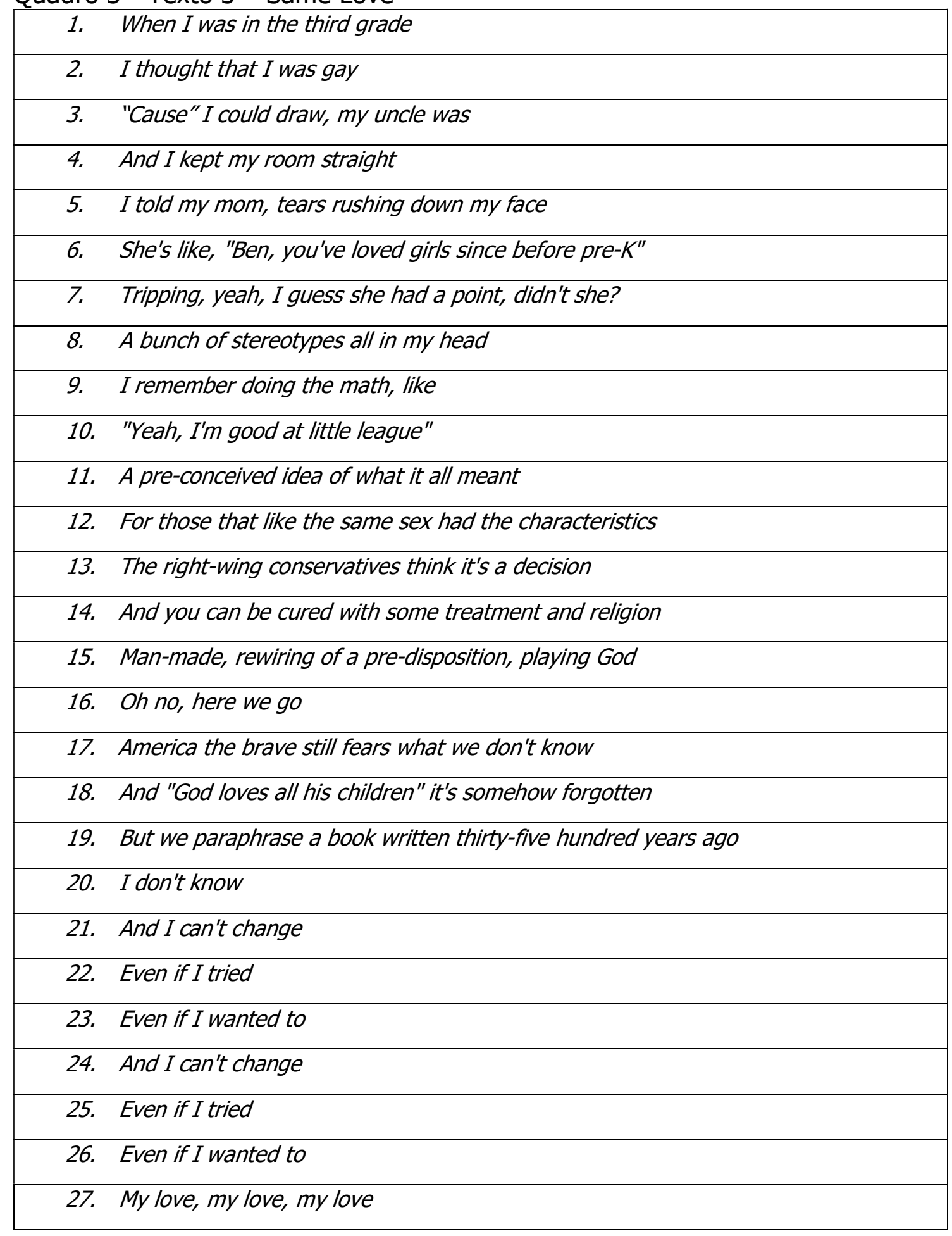


28. She keeps me warm

Fonte: The Heist (2012).

A análise do plano textual global do Texto 3 pode ser apresentada da seguinte maneira:

a) a canção se inicia com a narração de um episódio no qual o enunciador acreditou ser homossexual, baseado em estereótipos, sendo desmentido pela sua mãe em seguida (linhas 1-6)

b) o enunciador então reconhece que os parâmetros utilizados para que ele acreditasse ser homossexual eram na verdade estereótipos (linhas 7-12)

c) o enunciador endereça o discurso político conservador e religioso, que considera a homossexualidade enquanto algo a ser tratado, curado, apontando que o país ainda tem medo desse grupo social por ele ser desconhecido (linhas 13-17)

d) focalizando novamente o discurso religioso, que condena a homossexualidade, o enunciador o questiona (18-20)

e) o enunciador finaliza a canção ao dizer que não conseguiria mudar sua identidade, mesmo se quisesse (linhas 21-28)

Já a canção-rap intitulada "Animal Style" (estilo animal), encontra-se no disco "Love \& Rockets, Volume 1: The Transformation"(2011), sétimo álbum do rapper Murs. A canção obteve grande repercussão após o lançamento de seu videoclipe em que o rapper, publicamente heterossexual, aparece beijando um ator do sexo masculino. No que tange à materialidade sonora da canção, a faixa percussiva é proeminentemente marcada, com um andamento acelerado. Há 
"MC's de verdade não desejam sociedades sem diversidade": o rap LGBT nas aulas de língua inglesa

influências do blues e do sou/no padrão rítmico. A letra da canção é transcrita a seguir, enumerada para fins de análise: 
Quadro 4 - Texto 4 - Animal Style (5m25s), Murs, disco Love \& Rockets, Volume 1: The Transformation, Embassy the Hitmaker \& Royal P.

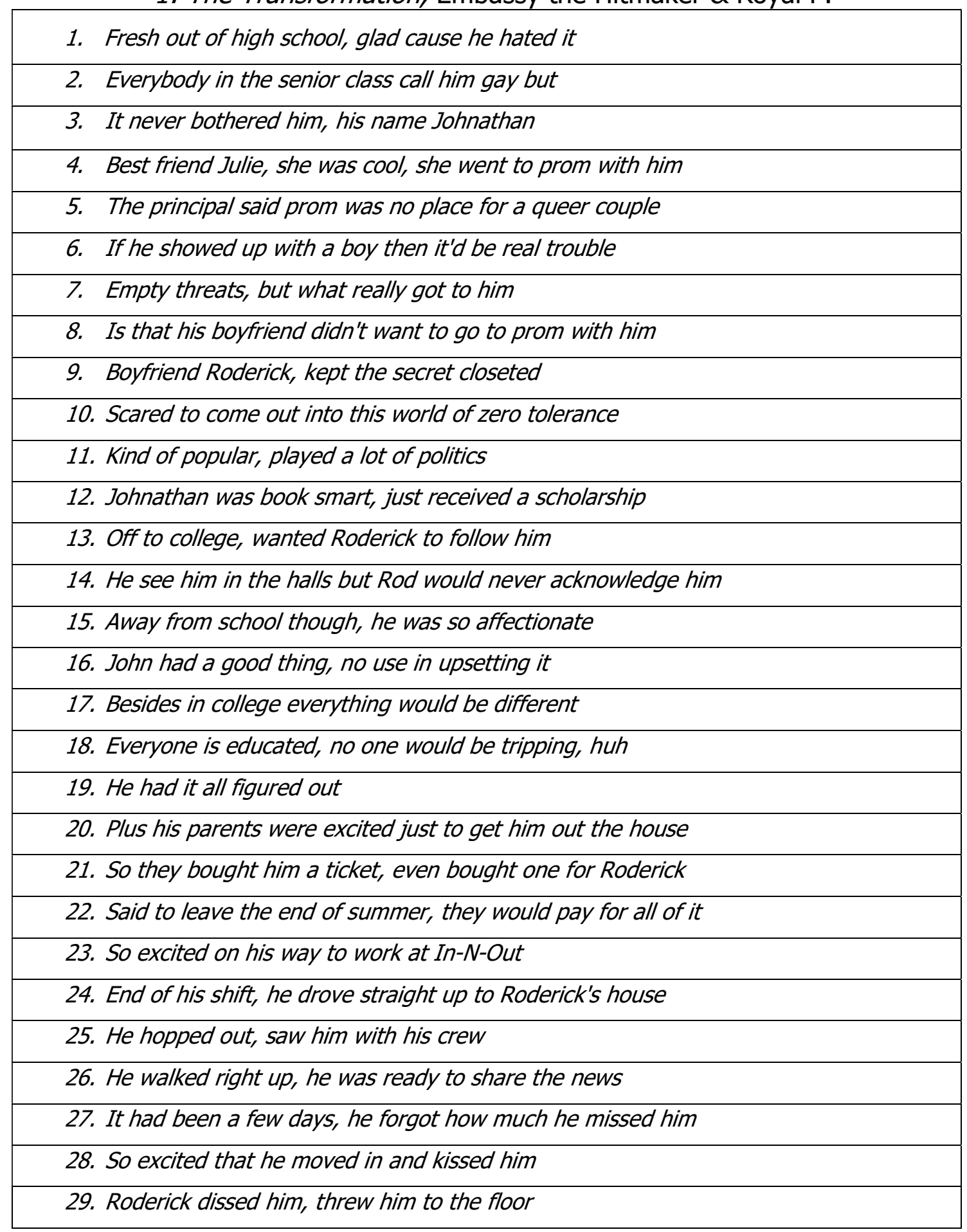


30. He said, "you faggot! What'd you have to do that for?"

31. Looked at his "homies", "You know I'm not gay"

32. They just shook their heads, turned and walked away

Fonte: Love... (2011).

A análise do plano textual global do Texto 4 pode ser apresentada da seguinte maneira:

a) a canção se inicia com a apresentação de um personagem (Johnathan) que está terminando seus estudos e que era chamado de gay pelos colegas de classe (linhas 1-3)

b) o personagem anteriormente introduzido é impedido pelo diretor de ir ao baile de formatura com seu namorado, tendo que ir com a sua melhor amiga. Johnathan se incomoda com o fato de seu namorado recusar ir ao baile de formatura com ele (linhas 4-8)

c) o personagem do namorado (Roderick) é apresentado enquanto um garoto popular que esconde o seu namoro com Johnathan (linhas 911)

d) Johnathan recebe uma bolsa de estudos em uma universidade e quer que o namorado o acompanhe (linhas 12-13)

e) a relação entre os dois rapazes é descrita: Roderick ignora o namorado na escola, mas é carinhoso fora dela. Os planos de Jhonathan para o futuro são revelados, onde ele poderá ficar com o namorado sem preocupações (linhas 14-19)

f) os pais de Jhonathan compram as passagens para que os dois garotos possam ir à universidade juntos, e ele vai até a casa do namorado dar a notícia (linhas 20-24) 
g) Jhonathan encontra o namorado após o trabalho com seus amigos, e o beija (25-28)

h) Roderick o joga no chão, envergonhado por ter sido beijado na frente dos amigos, e diz não ser gay, enquanto seus amigos vão embora (2932)

Assim como nos textos 1 e 2, o texto 3 traz a presença do discurso religioso ao discutir a questão da diversidade sexual (linhas 14-19). Apesar de ambos os textos tratarem da opressão originada pela identidade homossexual, a opressão representada parece partir de diferentes instâncias da vida pública. No texto 3, o discurso político e religioso é enfocado (linhas 13-15), enquanto no texto 4, a opressão parece advir do arranjo social da periferia, onde o mundo discursivo narrado se localiza, marcado pelo uso de gírias características dessa comunidade (crew, homies). Ademais, o contexto escolar aparece em ambos os textos, o que pode indicar a escola enquanto notoriamente um espaço de agressões para indivíduos homossexuais.

O papel social dos enunciadores dos textos 3 e 4 também é similar, assim como o objetivo da interação verbal. Tanto Macklemore quanto Murs são heterossexuais e já se pronunciaram em favor da comunidade LGBTQ+. Eles, desta maneira, configuram-se enquanto aliados ao movimento social, ainda que não pertençam a essa comunidade. Assim, eles lançam mão da identidade homossexual do outro para promover a discussão de gênero, o que implica um distanciamento entre o mundo discursivo e o mundo ordinário em que a ação de fala se inscreve.

Desta maneira, tanto no texto 3 quanto no texto 4, as coordenadas que organizam o conteúdo temático estão em disjunção às coordenadas do mundo ordinário. Isso se caracteriza pela ausência de dêiticos de tempo e espaço, e pela Entretextos, Londrina, v. 19, n. 1, p. 109- 142 Dossiê Temático/ 2019 
criação de um mundo outro ao mundo da ação da linguagem. Este é acessado pelo texto e é independente do mundo ordinário. Assim, os textos 3 e 4 estão localizados do mundo discursivo do narrar.

No que tange às instâncias de agentividade, o actante do texto 3 se encontra implicado, o que pode ser notado pelo uso da primeira pessoa e dos pronomes possessivos $(I, m y)$. Já no texto 4 , há a ausência das marcas de agentividade do actante, o que o posiciona em autonomia em relação aos parâmetros de ação da linguagem.

É importante notar que no texto 4, o actante está implicado ao contar a construção de sua identidade heterossexual ao entrar em conflito com os estereótipos. Não obstante, ao falar da identidade homossexual, há um distanciamento (those that like the same sex). Da mesma maneira, no texto 3 há a narração de uma história de conflito e preconceito por conta da sexualidade, todavia essa história é representada por personagens fictícios, e não pela representação do actante. Assim, o texto 3 caracteriza-se como um relativo interativo, enquanto o texto 4 caracteriza-se como uma narração.

\section{O Rap-LGBT no Ambiente Escolar}

O estudo e a compreensão do gênero canção-rap perpassa a própria compreensão da realidade de sujeitos periféricos, que possuem uma longa história de silenciamento e subjugação. É uma realidade que está muitas vezes alheia às camadas mais privilegiadas da sociedade e que, portanto, não costuma chegar ao ambiente escolar. O movimento hip-hop, assim, tem um alto apelo educacional, uma vez que oferece uma alternativa informal à educação formal (representada pela escola), pela qual indivíduos marginalizados tendem a não se sentir representados (AU, 2005; POWELL, 1991). Esse processo educacional que Entretextos, Londrina, v. 19, n. 1, p. 109- 142 Dossiê Temático/ 2019 
o hip-hop apresenta compreende a criação de novos espaços seguros, novas identidades não-hegemônicas legítimas, novos modos de ser, de agir e de se apresentar ao mundo - que não encontram precedentes na educação formal.

Intervenções como a de Lenharo (2016) revelam a carga de representatividade que esses textos trazem, na medida em que são produções de sujeitos que não costumam encontrar representação em espaços formais ou canônicos - como a escola, por exemplo. A análise aqui tecida corrobora com essa visão, na medida em que apresenta exemplos de textos pertencentes ao gênero canção-rap nos quais o papel social do enunciador é muito bem delimitado - sua identidade é exposta como uma medalha de honra, não como vergonha ou pecado.

É nesse sentido que a discussão da diversidade sexual ganha força quando aliada ao gênero canção-rap, já que este tem uma longa história de fazer ouvir vozes silenciadas, o que envolve uma tomada de consciência acerca do lugar de fala desses sujeitos. Nas palavras de Fonseca:

O rap produzido, em sua maioria, nas periferias de cidades brasileiras, traz em seu discurso ressonâncias, indícios, dessa tomada de consciência por parte daqueles que têm sua identidade marcada pelo signo de algum tipo de exclusão. A identidade da periferia entrou em foco, ou melhor, as identidades. Ganhou a atenção das classes médias e altas e foi elevada a estatuto moral para sobreviver no inferno. (FONSECA, 2011, p. 222).

A tomada de consciência mencionada por Fonseca não pode se estabelecer senão linguisticamente. Ela envolve a leitura crítica do mundo ao seu redor, e a apropriação dos signos que demarcam esse sujeito identitariamente, enquanto periférico - ou enquanto LGBT, para que ele possa mobilizar essa identidade no momento de seu agir. 
Em sua sócio-história, textos do gênero rap se configuraram como uma alternativa à educação para a juventude negra, uma vez que a escola não parecia dar conta de suas necessidades (AU, 2005; POWELL, 1991). Na contemporaneidade, todavia, as questões de exclusão e marginalização possuem um caráter interseccional. Aliada às questões raciais e sociais, as questões da diversidade sexual e de gênero configuram-se enquanto elemento pungente. Como um instrumento de representação e como um espaço seguro para a construção de uma identidade não-hegemônica legítima, o rap pode servir como uma alternativa para a juventude LGBT a uma escola que não reconhece, não valoriza e deslegitima a sua identidade.

\section{Conclusão}

Longe de esgotar todas as possibilidades do gênero, buscamos explorar neste trabalho as representações presentes em textos do gênero canção-rap para a discussão de questões de diversidade sexual nas aulas de língua inglesa. Desta maneira, buscou-se colaborar com a instrumentalização dos educadores que se preocupam com a questão da diversidade no ambiente escolar, de modo a apresentar novas possibilidades.

É importante salientar que, após a análise das canções-rap de nosso corpus, foi possível indicar uma distinção na mobilização do conteúdo temático entre as canções em língua portuguesa e em língua inglesa. Notou-se que, quando o tema da diversidade sexual é tratado, as canções-rap do contexto brasileiro referenciam a identidade homossexual do actante, ou seja, elas falam de si. Os textos em língua inglesa, por sua vez, apresentam um distanciamento em relação ao tema e abordam a questão ao falar da alteridade homossexual, do outro. Diante disso, é vital que se reflita acerca do lugar social ocupado pelos Entretextos, Londrina, v. 19, n. 1, p. 109- 142 Dossiê Temático/ 2019 
enunciadores, no objetivo dessa interação e na participação social proporcionada aos estudantes, ao levar esse gênero para a sala de aula.

O verso da canção "Quebrada Queer" que serve de título a esse trabalho representa, mais do que um desejo ou um pedido, um projeto de sociedade um projeto no qual a escola tem papel central, ainda que não seja o único. Nesse sentido, a teoria do ISD tem muito a contribuir ao fornecer instrumentos para que o professor de línguas estrangeiras aborde as possibilidades de construção de representações mais diversas que incorporem a voz da periferia, refletindo e refratando o contexto no qual os alunos estão incluídos. A criação de um rap envolve menos a interiorização de prescrições e mais a compreensão da ação de linguagem estabelecida nessa situação comunicativa. A partir dessa compreensão e da reflexão acerca dos papéis sociais exercidos por esses enunciadores é que a diversidade sexual e o rap podem chegar no contexto escolar.

Todavia, essa condição implica uma série de fatores. Ainda que a pluralidade de vozes e de modos de existir não possa ser construída sem uma escola mais justa e diversa, o âmbito escolar, tão somente, não pode ser o único responsável pela seguridade do respeito à diversidade. É preciso que, assim como os "MC's de verdade", pensemos uma sociedade diversa tanto quanto pensamos uma escola diversa. Diante disso faz-se clara a importância da formação de alunos críticos, para que eles possam se transformar em cidadãos críticos e que sua agência ultrapasse os muros da escola e se converta em uma participação social e política ativa e crítica. Nas palavras do inestimável educador Paulo Freire (2000, p. 67): "[s]e a educação sozinha não transforma a sociedade, sem ela tampouco a sociedade muda".

\section{Referências}


"MC's de verdade não desejam sociedades sem diversidade": o rap LGBT nas aulas de língua inglesa

APPLE MUSIC PREVIEW. The heist. Disponível em: https://music.apple.com/us/album/the-heist/560148910. Acesso em: 8 nov. 2018.

AU, Wayne. Fresh out of school: rap music's discursive battle with education. The Journal of Negro Education, Washington, v. 74, n. 3, p. 210-220, 2005.

BAKHTIN, Mikhail. Estética da criação verbal. 2. ed. São Paulo: Martins Fontes, 1997.

BAKHTIN, Mikhail; VOLOSHINOV, Valentin. Marxismo e filosofia da linguagem. 7. ed. São Paulo: Hucitec, 1995.

BERGAMINI, Claudia Vanessa; FERNANDES, Frederico Augusto Garcia. O rap como voz da periferia londrinense: uma abordagem de produções poéticas orais. Revista Boitatá, Londrina, v. 1, n. 1, 2005.

BOURDIEU, Pierre; PASSERON, Jean-Claude. $A$ reprodução: elementos para uma teoria do sistema de ensino. 3. ed. Rio de Janeiro: Francisco Alves, 1970.

BRASIL. Câmara dos Deputados. LDB: lei de diretrizes e bases da educação nacional. 5. ed. Brasília, DF: Centro de Comunicação e Informação, Edições Câmara, 1996.

BRASIL. Ministério da Educação. Base nacional curricular comum: ensino médio. Brasília: MEC, 2017. Disponível em http://basenacionalcomum.mec.gov.br/wpcontent/uploads/2018/04/BNCC_EnsinoMedio_embaixa_site.pdf. Acesso em: 13 ago. 2018.

BRASIL. Ministério da Educação. Parâmetros curriculares nacionais. ensino médio: parte I. Brasília: Ministério da Educação, 2000.

BRONCKART, Jean-Paul. Atividade de linguagem, texto e discurso: por um interacionismo sociodiscursivo. São Paulo: Educ, 2003.

CÂNDIDO, Antônio. Literatura e sociedade: estudos de teoria e história literária. 8. ed. São Paulo: T. A. Queiroz, 2000.

CHONIN, Neva. Hip to homo-hop / Oakland's D/DC fuses gay and black identities with eyebrow-raising rhyme. SFGate, San Francisco, 16 Dec. 2001. Disponível em: https://www.sfgate.com/entertainment/article/Hip-to-homohop-Oakland-s-D-DC-fuses-gay-and-2839793.php. Acesso em: 13 ago. 2018. 
"MC's de verdade não desejam sociedades sem diversidade": o rap LGBT nas aulas de língua inglesa

FONSECA, Ana Silva Andreu. Com que currículo eu vou pro rap que você me convidou? Revista do Instituto de Estudos Brasileiros, São Paulo, n. 62, p. 91111, dez. 2015.

FONSECA, Ana Silva Andreu. Versos violentamente pacíficos: o rap no currículo escolar. 2011. Tese (Doutorado em Linguística Aplicada) - Universidade Estadual de Campinas, Campinas, 2011.

FREIRE, P. Pedagogia da indignação: carta pedagógica e outros escritos. São Paulo: Unesp, 2000.

GROOVE, Gloria. O proceder. 2017. Disponível em: https://www.letras.mus.br/gloria-groove/discografia/o-proceder-2017/. Acesso em: 8 nov. 2018.

GRUPO GAY NA BAHIA-GGB. Mortes violentas de LGBT no Brasil: relatório 2017. Disponível em: https://homofobiamata.files.wordpress.com/2017/12/relatorio2081.pdf. Acesso em: 13 ago. 2018.

HALL, Stuart. A identidade cultural na pós-modernidade. 10. ed. Rio de Janeiro: DP\&A, 2005.

LADO A. Grupo Quedrada Queer lança videoclipe de rap. 2018. Disponível em: https://revistaladoa.com.br/2018/04/cultura/pabllo-vittar-lanca-videoclipeemocionante-do-single-indestrutivel/. Acesso em: 8 nov. 2018.

LENHARO, Rayane Isadora. Participação social por meio da música e da aprendizagem de língua inglesa em um contexto de vulnerabilidade social. 2016. Dissertação (Mestrado em Estudos da Linguagem) - Universidade Estadual de Londrina, Londrina.

LOVE \& rockets 1: the transformation. Amazon Music. 2011. Disponível em: https://www.amazon.com/Love-Rockets-1-TransformationMurs/dp/B005JLNAJ8. Acesso em: 8 nov. 2018.

NASCIMENTO, Elvira Lopes; PINHEIRO, Elaine Cristina. Rap - um gênero textual para letramento de reexistência. In: CONGRESSO NACIONAL DE LINGUAGENS EM INTERAÇÃO MÚLTIPLOS OLHARES, 4., 2013, Maringá, PR. Anais [...]. Maringá: Universidade Estadual de Maringá, 2013. Disponível em: www.dle.uem.br/conali2013/trabalhos/78t.pdf. Acesso em: 8 nov. 2018. 
OLIVEIRA, Paul Parra Alves. Linn da quebrada e Pajubá: hipermidiatização e música queer periférica. In: PENSACOM BRASIL, 1., 2017, São Paulo. Anais [...]. São Paulo: Sociedade Brasileira de Estudos Interdisciplinares da Comunicação, 2017. Disponível em: http://portalintercom.org.br/anais/pensacom2017/lista_area_gt4.htm. Acesso em: 8 nov. 2018.

PARADA, Sara Guerreiro; FERNANDES, Frederico. O freestyle em perspectiva: análise das práticas orais de rappers londrinenses. Revista Boitatá, Londrina, v. 2, n. 4, 2007.

POWELL, Catherine Tabb. Rap music: an education with a beat from the street. The Journal of Negro Education, Washington, DC, v. 60, n. 3, p. 245-259, 1991.

THE HEIST. Macklemore e Ryan Lewis. Seattle, WA: Macklemore LLC, 2012. CD, download digital (64:09, versão padrão, 76:08, versão especial). 